\title{
PENGARUH PENDIDIKAN DAN DUKUNGAN SUAMI TERHADAP KELENGKAPAN ANC PADA IBU HAMIL DI WILAYAH KERJA PUSKESMAS PEUKAN BADA KABUPATEN ACEH BESAR TAHUN 2016
}

\author{
Fithriany ${ }^{1}$, Cut Yuniwati ${ }^{2}$ \\ ${ }^{1}$ Dosen Poltekkes NAD Jurusan Kebidanan Banda Aceh \\ ${ }^{2}$ Dosen Poltekkes NAD Jurusan Kebidanan Banda Aceh
}

\begin{abstract}
Abstrak
Latar Belakang : Salah satu usaha yang dapat dilakukan untuk memantau kemajuan kehamilan sehingga dapat dipastikan kesehatan ibu dan janin dengan melakukan pemeriksaan kehamilan (antenatal care). Hasil studi pendahuluan di wilayah kerja Puskesmas Pekan Bada Kabupaten Aceh Besar data tahun 2014 cakupan K4 sebesar 43,5\% dan data 2015 cakupan K4 hanya 78\% (masih jauh dari data cakupan yang diharapkan oleh Departemen Kesehatan yaitu 90\%). Dari beberapa orang bidan di desa yang cakupan K4 nya masih kurang menyatakan bahwa ibu-ibu hamil tersebut tidak mau datang ke Puskesmas atau Polindes untuk memeriksakan kehamilannya.Sebagian besar dari ibu hamil yang diperiksa di Puskesmas dan Polindes hanya datang sendiri tanpa ditemani oleh suami atau anggota keluarga lainnya. Penelitian ini bertujuan untuk menganalisis pengaruh pengetahuan ibu dan dukungan suami terhadap pemeriksaan kehamilan. Jenis penelitian adalah penelitian cross-sectional. Penelitian ini dilakukan di wilayah kerja Puskesmas Pekan Bada Kabupaten Aceh Besar. Sampel dalam penelitian ini adalah seluruh ibu hamil di wilayah kerja Puskesmas Pekan Bada yang memiliki buku KIA. Jumlah sampel97 ibu hamil, dengan tehnik pengambilan sampel total sampling. Analisa data menggunakan uji Chi-quare pada taraf kepercayaan $95 \%(\alpha<0,05)$.Hasil Penelitian : Dari hasil penelitian menunjukkan bahwa ibu yang melakukan pemeriksaan ANC lengkap persentasenya lebih banyak dijumpai ibu yang berpengetahuan baik, yaitu $76 \%$ ( $p$ value 0,01 ). Dukungan keluarga bahwa ibu yang memeriksa ANC lengkap persentasenya lebih banyak dijumpai ibu yang mendapat dukungan keluarga yaitu 75,9\% (p value =0,011).Kesimpulan dan Saran :Terdapat pengaruh Pengetahuan dan dukungan suami terhadap kelengkapan pemeriksaan ANC pada ibu hamil. Disarankan agar bekerja sama secara lintas sektor untuk peningkatan sosialisasi dan penyuluhan rutin tentang pemeriksaan kehamilan dengan mengikut sertakan suami.
\end{abstract}

Kata Kunci : Pengetahuan, Dukungan Suami, pemeriksaan ANC

\section{PENDAHULUAN}

Indikator keberhasilan pembangunan kesehatan dapat dilihat dari peningkatan atau penurunan derajat kesehatan.Salah satu indikator derajat kesehatan tersebut adalah Angka Kematian Ibu (AKI).Persoalan kematian yang terjadi disebabkan oleh pendarahan, eklamsi, aborsi, dan infeksi. Selain masalah medis, tingginya kematian ibu juga karena pemberdayaan perempuan yang kurang baik, latar belakang pendidikan perempuan, masalah ketidaksetaraan gender, nilai budaya, perekonomian serta rendahnya perhatian laki-laki terhadap ibu hamil dan melahirkan. Oleh karena itu, pandangan yang menganggap kehamilan adalah peristiwa alamiah perlu diubah secara sosiokultural.Sangat diperlukan upaya peningkatan pelayanan perawatan ibu.baik oleh pemerintah, swasta, maupun masyarakat terutama suami.Negara-negara di dunia memberi perhatian yang cukup besar terhadap AKI, sehingga menempatkannya di antara delapan tujuan yang dituangkan dalam Millenium Development Goals (MDGs), yang harus dicapai sebelum 2015.Komitmen yang ditandatangani 189 negara pada September 2000, pada prinsipnya bertujuan untuk meningkatkan taraf hidup dan kesejahteraan manusia (Yustina, 2007).

Menurut Profil kesehatan Indonesia (2010), AKI di Indonesia menunjukkan penurunan dari tahun 1994 yaitu 394/ 100.000 Kelahiran Hidup (KH) sampai dengan 2007 yaitu 228/ 100.000 KH. walaupun sudah terjadi penurunan AKI di Indonesia, namun angka tersebut masih menempatkan Indonesia pada peringkat 12 dari 18 negara ASEAN dan SEARO (South East Asia Region, yaitu: Bangladesh, Bhutan, Korea Utara, India, Maladewa, Myanmar, Nepal, Timor Leste, dan lainlain ). Di Aceh meskipun telah terjadi penurunan dibandingkan dengan sebelumnya, namun jumlah Angka Kematian Ibu (AKI) dan Angka Kematian Bayi (AKB) di Provinsi Aceh hingga saat ini masih tergolong tinggi. Berdasarkan data terakhir Desember 
2013, jumlah AKI di Aceh berkisar 190/100.000 dan AKB berkisar 30/1.000 .Karenanya, upaya pengurangan terus dilakukan oleh Pemerintah Aceh sebagai salah satu indikator Indeks Pembangunan Manusia (IPM) bidang kesehatan (Dinkes Provinsi Aceh, 2015).

Upaya untuk mempercepat penurunan AKI telah dimulai sejak akhir tahun 1980-an melalui program Safe Motherhood Initiative yang mendapat perhatian besar dan dukungan dari berbagai pihak baik dalam maupun luar negeri. Pada akhir tahun 1990-an secara konseptual telah diperkenalkan lagi upaya untuk menajamkan strategi dan intervensi dalam menurunkan AKI melalui Making Pregnancy Safer (MPS) yang dicanangkan oleh pemerintah pada tahun 2000. Strategi MPS memfokuskan pada 3 pesan yaitu: akses terhadap pelayanan oleh tenaga terampil, akses terhadap pelayanan rujukan jika terjadi komplikasi dan pencegahan kehamilan yang tidak diinginkan dan penanganan komplikasi terhadap keguguran (Dinkes, 2007).

Pesan pertama yaitu akses terhadap pelayanan oleh tenaga terampil, diharapkan semua ibu hamil dan bersalin ditolong oleh tenaga kesehatan.Pelayanan kesehatan pada ibu-ibu hamil meliputi pelayanan antenatal di semua fasilitas pelayanan dengan mutu sesuai standar.Salah satu usaha yang dapat dilakukan untuk memantau kemajuan kehamilan sehingga dapat dipastikan kesehatan ibu dan janin, dilakukan pemeriksaan kehamilan (antenatal care). Pemeriksaan kehamilan minimal 4 kali selama kehamilan dapat diketahui secara dini adanya kelainan atau komplikasi yang menyertai kehamilan, sehingga penanganan dapat dilakukan dengan tepat dan mencegah kematian ibu dan janin (Saifuddin, 2002).

AKI di Indonesia sesungguhnya bisa dicegah jika dilakukan perbaikan terhadap akses pelayanan kesehatan bagi ibu.Akses ibu hamil ke tempat pelayanan kesehatan juga dipengaruhi dengan adanya dukungan suami serta peran keluarga untuk membawanya ke pelayanan kesehatan disaat timbulnya masalah dalam kehamilan (Muslihatun, Mufdillah, Setiyawati, 2009).

Hasil studi pendahuluan di wilayah kerja Puskesmas Pekan Bada Kabupaten Aceh Besar data tahun 2014 cakupan K4 sebesar 43,5\% dan data 2015 cakupan K4 hanya 78\% (masih jauh dari data cakupan yang diharapkan oleh Departemen Kesehatan yaitu 90\%). Dari beberapa orang bidan di desa yang cakupan K4 nya masih kurang menyatakan bahwa ibu-ibu hamil tersebut tidak mau datang ke Puskesmas atau Polindes untuk memeriksakan kehamilannya.

Para ibu hamil tersebut baru akan memeriksakan kehamilan apabila kehamilannya sudah kelihatan dan biasanya pada usia kehamilan sudah memasuki trimester II (4-6 bulan), dan selama ini yang dilakukan bidan di desa adalah melakukan home visit (kunjungan rumah) untuk melakukan pemeriksaan kehamilan dan dilakukan apabila bidan mengetahui ibu tersebut hamil. Di wilayah kerja Puskesmas Pekan Bada sebagian besar pekerjaan para suami adalah
petani.Petani tidak setiap hari harus ke sawah.ada waktu luang yang bisa digunakan untuk mengantar istri periksa hamil. Sebagian besar dari ibu hamil yang diperiksa di Puskesmas dan Polindes hanya datang sendiri tanpa ditemani oleh suami atau anggota keluarga lainnya. Dengan menemani istri setiap kali periksakan hamil, suami mendapatkan informasi yang sangat penting bagi kehamilan, sehingga suami dapat memberikan dukungan kepada istri yang sedang hamil, yang pada kenyataannya tidak dilakukan oleh sebagian besar para suami di wilayah kerja Puskesmas Pekan Bada.

Penelitian ini bertujuan untuk mengetahui pengaruh pengetahuan ibu dan dukungan suami terhadap pemeriksaan ANC pada ibu hamil di Kecamatan Pekan Bada

\section{KERANGKA KONSEP}

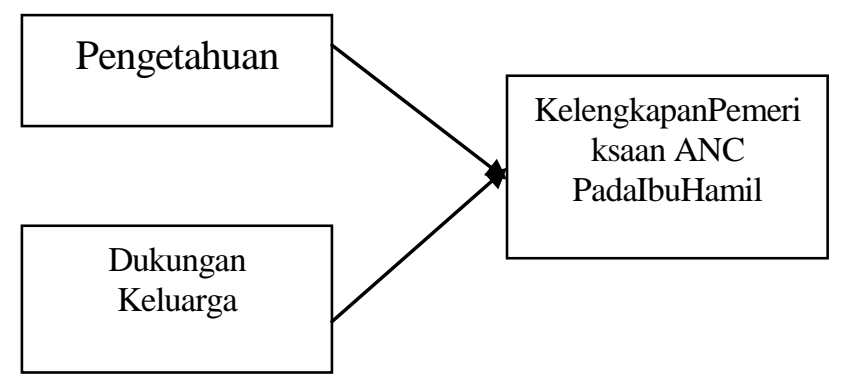

\section{Hipotesa}

1. Ada hubungan pengetahuan dengan kelengkapan pemeriksaan ANC pada ibu hamil Di Wilayah Kerja Puskesmas Peukan Bada Kabupaten Aceh Besar Tahun 2016.

2. Ada hubungan dukungan keluarga dengan kelengkapan pemeriksaan ANCpada ibu hamil Di Wilayah Kerja Puskesmas Peukan Bada Kabupaten Aceh Besar Tahun 2016.

\section{METODE PENELITIAN}

Jenis penelitian ini adalah survei dengan pendekatan cross sectional, merupakan penelitian dimana pengukuran atau pengamatan dilakukan pada saat bersamaan pada data variabel independen dan dependen (sekali waktu).

Penelitian ini telah dilakukan di Wilayah Puskesmas Peukan Bada Kabupaten Aceh Besar Tahun 2016

Tehnik pengambilan sampel akan dilakukan pada ibu hamil diwilayah kerja Puskesmas Peukan Bada Adapun teknik pengambilan adalah secara total Sampling yaitu sebanyak 97 orang ibu hamil yang memiliki buku KIA. Instrument penelitian menggunakan kuesioner. Analisis data menggunakan uji chi square pada tingkat kepercayaan $95 \%(\mathrm{p}<0,05)$. 


\section{HASIL DAN PEMBAHASAN}

Kelengkapan Pemeriksaan Anc

Tabel 5.1 Distribusi Frekuensi Kelengkapan Pemeriksaan ANC Ibu Hamil Di Wilayah Kerja Puskesmas Peukan Bada Kabupaten Aceh Besar Tahun 2016

\begin{tabular}{|c|c|c|c|}
\hline No & $\begin{array}{c}\text { Kelengkapan } \\
\text { Pemeriksaan } \\
\text { ANC } \\
\end{array}$ & $\mathbf{f}$ & $\begin{array}{c}\text { Persentase } \\
(\%)\end{array}$ \\
\hline 1. & Lengkap & 62 & 63,9 \\
\hline \multirow[t]{2}{*}{2.} & Tidak Lengkap & 35 & 36,1 \\
\hline & Total & 97 & 100 \\
\hline
\end{tabular}

Tabel 5.1 menunjukkan bahwa dari 97 responden sebagian besar lengkap melakukan ANC yaitu 63,9\% (62 responden).

Tabel 5.2 Distribusi Frekuensi Pengetahuan Pada Ibu Hamil Di Wilayah Kerja Puskesmas Peukan Bada Kabupaten Aceh Besar Tahun 2016

\begin{tabular}{clcc}
\hline No & Pengetahuan & f & $\begin{array}{c}\text { Persentase } \\
(\mathbf{\%})\end{array}$ \\
\hline 1. & Baik & 50 & 51,5 \\
2. & Kurang & 47 & 48,5 \\
\hline \multicolumn{2}{c}{ Total } & $\mathbf{9 7}$ & $\mathbf{1 0 0}$ \\
\hline
\end{tabular}

Tabel 5.1 menunjukkan bahwa dari 97 responden yang pengetahuan baik tentang ANC adalah $51,5 \%$ (50 responden), sedangkan yang pengetahuan kurang adalah $48,5 \%$ (47 responden).

Tabel 5.4 Distribusi Frekuensi Dukungan Keluarga Pada Ibu Hamil Di Wilayah Kerja Puskesmas Peukan Bada Kabupaten Aceh Besar Tahun 2016

\begin{tabular}{clcc}
\hline No & Dukungan Keluarga & f & $\begin{array}{c}\text { Persentase } \\
(\boldsymbol{\%})\end{array}$ \\
\hline 1. & Mendukung & 54 & 55,7 \\
2. & Tidak Mendukung & 43 & 44,3 \\
\hline \multicolumn{2}{c}{ Total } & $\mathbf{9 7}$ & $\mathbf{1 0 0}$ \\
\hline
\end{tabular}

Berdasarkan tabel 5.4 dapat diketahui bahwa dari 97 responden sebagian besar responden mendapat dukungan keluarga 55,7\% (54 responden)

A Hubungan Pengetahuan dengan Kelengkapan ANC Tabel 5.5 Hubungan Pengetahuan Dengan Kelengkapan Pemeriksaan ANC Pada Ibu Hami Di Wilayah Kerja Puskesmas Peukan Bada Kabupaten Aceh Besar Tahun 2016

\begin{tabular}{|c|c|c|c|c|c|c|c|c|}
\hline \multirow{3}{*}{ No } & \multirow{3}{*}{ Pengetahuan } & \multicolumn{4}{|c|}{$\begin{array}{c}\text { Kelengkapan } \\
\text { Pemeriksaan ANC }\end{array}$} & \multirow{2}{*}{\multicolumn{2}{|c|}{ Total }} & \multirow{3}{*}{$\begin{array}{c}P- \\
\text { Value }\end{array}$} \\
\hline & & \multicolumn{2}{|c|}{ Lengkap } & \multicolumn{2}{|c|}{$\begin{array}{c}\text { Tidak } \\
\text { Lengkap }\end{array}$} & & & \\
\hline & & $\mathbf{f}$ & $\%$ & $\mathbf{f}$ & $\%$ & $\mathbf{f}$ & $\%$ & \\
\hline 1. & Baik & 38 & 76 & 12 & 24 & 50 & 100 & \\
\hline \multirow[t]{2}{*}{2.} & Kurang Baik & 24 & 51,1 & 23 & 48,9 & 47 & 100 & 0,019 \\
\hline & Total & 62 & & 35 & & 97 & & \\
\hline
\end{tabular}

Tabel 5.5 menunjukkan bahwa ibu hamil yang mempunyai pengetahuan baik lebih besar persentase kelengkapan pemeriksaan ANC nya lengkap (70\%) di bandingkan ibu yang memiliki pengetahuan kurang baik hanya $(51,5 \%)$, dan secara statistik menunjukkan bermakna dengan $p$-value $=0,019 .(P<0,05)$

Hasil uji hubungan menunjukkan bahwa ada hubungan yang signifikan pengetahuan ibu hamil dengan kelengkapan pemeriksaan ANC.

\section{B. Hubungan Dukungan Keluarga Dengan Kelengkapan Pemeriksaan ANC}

Tabel 5.7 Hubungan Dukungan Keluarga Dengan Kelengkapan Pemeriksaan ANC Pada Ibu Hamil Di Wilayah Kerja Puskesmas Peukan Bada Kabupaten Aceh Besar Tahun 2016

\begin{tabular}{|c|c|c|c|c|c|c|c|c|}
\hline \multirow{3}{*}{ No } & & \multicolumn{4}{|c|}{$\begin{array}{c}\text { Kelengkapan } \\
\text { Pemeriksaan ANC }\end{array}$} & \multirow{2}{*}{\multicolumn{2}{|c|}{ Total }} & \multirow{3}{*}{$\begin{array}{c}P- \\
\text { Value }\end{array}$} \\
\hline & & \multicolumn{2}{|c|}{ Lengkap } & \multicolumn{2}{|c|}{$\begin{array}{c}\text { Tidak } \\
\text { Lengkap }\end{array}$} & & & \\
\hline & & f & $\%$ & $\mathbf{f}$ & $\%$ & $\mathbf{f}$ & $\%$ & \\
\hline 1. & Mendukung & 41 & 75,9 & 13 & 24,1 & 54 & 100 & \\
\hline 2. & $\begin{array}{l}\text { Tidak } \\
\text { Mendukung }\end{array}$ & 21 & 48,8 & 22 & 51,2 & 43 & 100 & 0,011 \\
\hline & Total & 62 & & 35 & & 97 & & \\
\hline
\end{tabular}

Berdasarkan tabel 5.7 dapat diketahui bahwa ibu yang mendapatkan dukungan keluarga persentasenya lebih besar kelengkapan pemeriksaan ANC pada kategori lengkap (75,9\%)dibandingkan dengan ibu yang tidak mendapatkan dukungan keluarga, dan secara statistik menunjukkan perbedaan yang bermakna dengan $p$-value $=0,011 .(P<0,05)$, berarti ada hubungan yang signifikan dukungan Keluarga dengan kelengkapan pemeriksaan ANC pada ibu hamil.

\section{PEMBAHASAN}

\section{A. Hubungan Pengetahuan ibu dengan Kelengkapan ANC}

Pengetahuan (Knowledge) juga diartikan sebagai hasil penginderaan manusia atau hasil tahu seseorang terhadap objek melalui indra yang dimilikinya (mata, hidung dan sebagainya), dengan sendirinya pada waktu pengindraan sehingga menghasilkan pengetahuan. Hal tersebut sangat dipengaruhi oleh intensitas perhatian dan persepsi terhadap objek (Notoatmodjo, 2007).

Penelitian ini sesuai dengan penelitian fitrihanda (2012) ada hubungan antara pengetahuan dengan kelengkapan pemeriksaan ANC pada ibu hamil.

Penelitian yang sama juga dilakukan oleh Eva (2012) dengan hasil ada hubungan yang signifikan antara pengetahuan dengan kelengkapan pemeriksaan ANC pada ibu hamil.

\section{B. Hubungan Dukungan keluarga dengan kelengkapan ANC \\ Dukungan keluarga adalah informasi verbal,} sasaran, bantuan yang nyata atau tingkah laku yang 
diberikan oleh orang-orang yang akrab dengan subjek didalam lingkungan sosialnya atau yang berupa kehadiran dan hal yang dapat memberikan keuntungan emosional atau pengaruh pada tingkah laku penerimaannya. Dalam hal ini orang yang merasa memperoleh dukungan sosial, secara emosional merasa lega diperhatikan, mendapat saran atau kesan yang menyenangkan pada dirinya(Suparyanto, 2012).

Penelitian ini sesuai dengan penelitian Simkhada et al., (2008), wanita yang mendapatkan dukungan dari orang-orang terdekat selama kehamilan dua kali lebih mungkin untuk hadir dalam melakukan pemeriksaan kehamilan dibandingkan dengan wanita yang tidak mendapatkan dukungan.Demikian pula penelitian Simanjuntak (2002), menyatakan bahwa ada hubungan yang bermakna antara dukungan suami terhadap kunjungan antenatal yang sesuai.

Hasil penelitian sesuai dengan penelitian Erci (2003), Sosial support berpengaruh secara signifikan terhadap jumlah kunjungan antenatal care. Dukungansosialyang tidak memadaimerupakanhambatanuntukmemperoleh pelayanan kehamilan.Dukungansosialyang

diterimadarikeluargameningkatkanjumlah

kunjungandanibu hamil melakukan kunjungan lebih awal.

\section{PENUTUP}

\section{Kesimpulan}

1. Terdapat hubungan yang signifikan antara pengetahuan dengan kelengkapan pemeriksaan ANC pada ibu hamil di Wilayah Kerja Puskesmas Peukan Bada Kabupaten Aceh Besar Tahun 2016 ( $\mathrm{p}$ value $=0,01)$

2. Terdapat hubungan yang signifikan antara dukungan keluarga dengan kelengkapan pemeriksaan ANC pada ibu hamil di Wilayah Kerja Puskesmas Peukan Bada Kabupaten Aceh Besar Tahun 2016 ( $p$ value $=0,019$ )

\section{Saran}

Berdasarkan kesimpulan diatas, maka dapat diberikan saran atau rekomendasi sebagai berikut:

1. Kepada Dinas Kesehatan Dati II Kabupaten Aceh Besar perlu membuat kebijakan dengan mengikut sertakan suami dalam upaya peningkatan cakupan pemeriksaan kehamilan, seperti pembentukan desa siaga, peningkatan pemanfaatan buku KIA.

2. Kepada Puskesmas perlu melakukan:

a. Bekerja sama dengan KUA kecamatan untuk melakukan konseling pranikah sehingga pasangan tahu usia yang baik untuk hamil dan melahirkan.

b. Bekerja sama dengan tokoh agama (tengku atau imam mesjid) dalam memberikan penyuluhan untuk meningkatkan dukungan dan peran serta suami dalam pemeriksaan kehamilan.

c. Menyediaan media sumber informasi berupa audio visual tentang pelayanan antenatal care bagi ibu dan pentingnya dukungan suami di ruang tunggu Puskesmas.

d. Peningkatan sosialisasi dan penyuluhan rutin tentang pemeriksaan kehamilan dengan mengikut sertakan para suami, agar suami paham bahwa dukungan suami mempunyai andil dalam peningkatan cakupan pemeriksaan kehamilan.

e. Membuat kebijakan untuk bidan yang bertugas di desa melakukan kunjungan rumah untuk pemeriksaan ibu hamil.

3. Penelitian ini hanya melihat dukungan suami dari persepsi ibu, perlu penelitian lanjutan tentang partisipasi suami sehingga dapat benar-benar diketahui hal yang paling berpengaruh terhadap kunjungan pemeriksaan kehamilan agar dapat memberi kontribusi terhadap pengetahuan dan khazanah riset ilmiah di masa akan datang.

\section{DAFTAR PUSTAKA}

Dinkes Prov. NAD, 2015. Profil Kesehatan Provinsi Nanggroe Aceh Darussalam, Banda Aceh.

Erci B. (2003). Barrier To Utilization of Prenatal care Service In Turkey, Journal In Nursing Scholarship.

Fitrihanda, 2013.Faktor-Faktor Yang Berhubungan Dengan Pelaksanaan ANC Terintegrasi Di Wilayah Kerja Puskesmas Krueng Barona Jaya. Skripsi

Hamid, Z.M, (2003), Hubungan pengetahuan dan Sikap Ibu dengan Pemeriksaan Kehamilan di Kabupaten Serang Provinsi Banten, Thesis, Universitas Indonesia, Jakarta.

Hastono, 2010.Statistik Kesehatan.Edisi Revisi. Jakarta Kusmiyanti, 2008.Standar Pelayanan Kebidana. Jakarta.Rinika Cipta

Lubis, 2009.Konsep Obstetri dan Ginekologi Sosial Indonesia, Jakarta, EGC.

Muslihatun W.N., Mufdillah, Setiyawati N, (2009), Dokumentasi Kebidanan, fitramaya, Jogjakarta.

Maramis, 2009. Pendidikan Dan Perilaku Kesehatan.. Rineka Cipta. Jakarta.

Mubarak, 2007. Promosi Kesehatan Dan Ilmu Perilaku. Rineka Cipta. Jakarta.

Notoatmodjo, 2007. Promosi Kesehatan Dan Ilmu Perilaku. Rineka Cipta. Jakarta

Simkhada B, Teijlingen ER, Porter M, Simkhada P., (2007), Factors Affecting The Utilization of Antenatal Care in Developing Countries: Systematic Review of The Literature, $\underline{J A d v}$ Nurs.2008 Feb; 61(3) :244-60, http://www.ncbi.nlm.nih.gov/pubmed/

Simanjuntak T., (2002), Faktor-Faktor yang Berhubungan dengan Kunjungan Antenatal K4 di Kota Medan Provinsi Sumatera Utara, Thesis, Universitas Indonesia, Jakarta.

Yustina I, (2007). Upaya Strategis Menurunkan AKI dan AKB. Jurnal Wawasan Ilmu-Ilmu Sosial, 13 (2) : $182-187$. 